\title{
Teaming up Internationally to Optimize Wild and Hatchery Pacific Salmon Production in a Future of Changing Ocean Ecosystems-the International Year of the Salmon (IYS)
}

\author{
Richard J. Beamish \\ Fisheries and Oceans Canada, Pacific Biological Station, 3190 Hammond Bay Road, Nanaimo BC V9T 6N7 \\ Canada
}

Keywords: International Year of the Salmon, International Cooperative Research

\section{Introduction}

I like to say that we know a lot about Pacific salmon, but what we need to know most, we mostly do not know. This means that we mostly are not able to forecast the abundances of returning adult Pacific salmon. Pacific salmon catches are at historic high levels, however there is no understanding of why the abundances continue to be so high or how long the high abundances will last. We are not able to make consistently reliable forecasts because we do not understand the basic mechanisms that regulate the population dynamics of Pacific salmon. In particular, we do not understand how climate and a changing ocean ecosystem will affect salmon abundances. In the past, we believed that adult abundances were most closely related to the number of smolts that entered the ocean. It was only a little over 20 years ago that we started to discover that ocean ecosystems profoundly affected production with impacts that were not random. We now realize that greenhouse gas induced changes in climate in the immediate future will alter ocean ecosystems, adding to the complexity of forecasting without an understanding of the mechanisms regulating survival in the ocean.

It is important that the problem of forecasting Pacific salmon production be related to hatchery as well as to wild Pacific salmon. Understanding the factors affecting the ocean survival of hatchery fish often receives less attention and some consider that hatchery fish are inherent in the mechanisms that regulate wild salmon survival in the ocean. Recent estimates are that about $40 \%$ of the biomass of all Pacific salmon in the ocean originates from hatcheries (Ruggerone and Irvine, 2018). As abundances of all Pacific salmon are at historic high levels (Ruggerone and Irvine, 2018) and the number of hatchery fish released into the ocean has not changed much since the late 1980s (data from NPAFC Pacific salmonid hatchery release statistics, updated 31 July 2018), it appears that hatchery fish are almost of equal importance to wild salmon when looking into the future of Pacific salmon production. Thus, it is the purpose of my presentation to focus attention on the need to identify the mechanisms that regulate the abundances of wild and hatchery Pacific salmon. I am suggesting that this can best be done by establishing international teams of researchers. The International Year of the Salmon can be the opportunity to establish these teams.

Why international cooperation is urgent

Most of us are familiar with the anomalous warming that occurred late in 2013 in the eastern Pacific and combined with the El Niño of 2014-2016, produced some of the warmest ocean temperatures on record over an area from Alaska to Mexico (Fig. 1). Recently published research (Wang et al. 2018) shows that the warming event of 2013-2014, often referred to as the "blob" may be related to sea ice loss in the Arctic and thus could become more common. There is considerable evidence that the warming of 2013-2014 reduced nutrient levels, resulting in poor production of Pacific salmon in a number of areas. Thus, there is an urgency in understanding how population size is determined in the ocean so that the impacts of these and other extreme climate/ocean events on wild and hatchery salmon are understood in advance of adult returns. In the past, finding out why population trends and synchronies occurred would have been nice to know, but this understanding is now urgently needed.

I will begin by providing examples of production trends to show that the problem of understanding the mechanisms regulating Pacific salmon production is best dealt with as an international problem. Next, I want to show that the production of hatchery fish needs to be re-evaluated to be able to adapt to the expected ocean ecosystem changes. I propose that adapting hatchery production to a future of changing ocean ecosystems is also an international problem. In my third topic, I will speculate on a mechanism that may be fundamental to both hatchery and wild production. I conclude with comments on why the International Year of the Salmon can be the beginning of international teamwork that will ensure that each country has the information to make management decisions that optimize economic opportunities for hatchery and wild-based fisheries. We cooperate internationally to solve complex human medical issues and we now need to use the same kind of cooperation to ensure that the future 
stewardship of Pacific salmon anticipates the impacts of ocean changes rather than being continually surprised by unexpected adult returns.
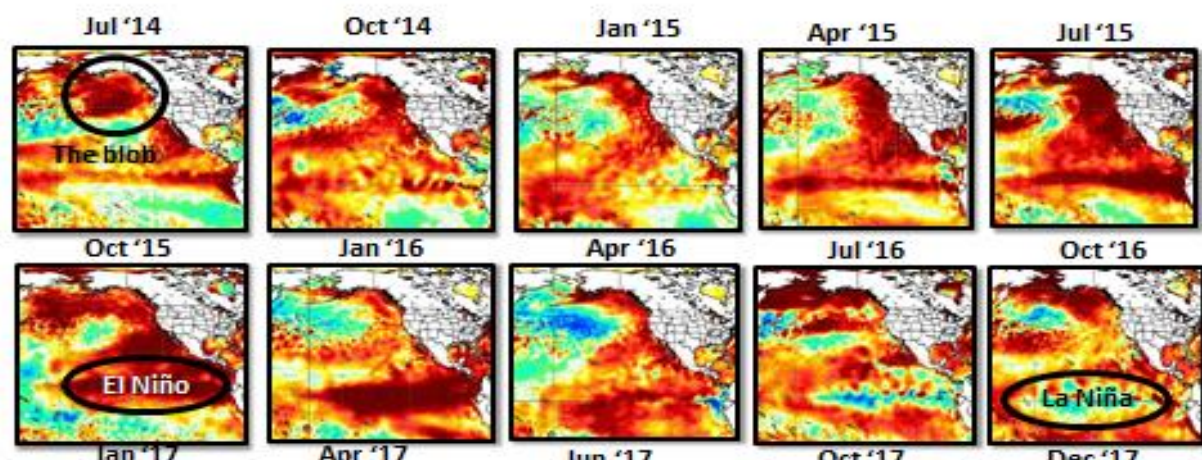

Jul' 16

Oct '16

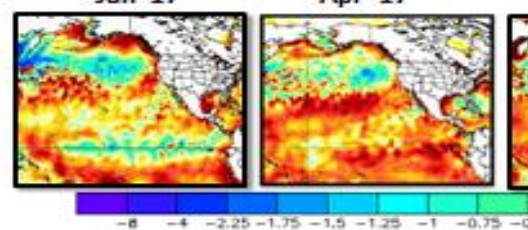

Jun '17

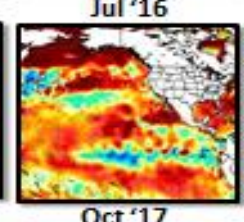

Oct $^{\prime} 17$

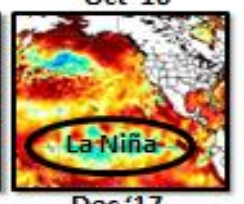

$\operatorname{Dec}^{\prime} 17$
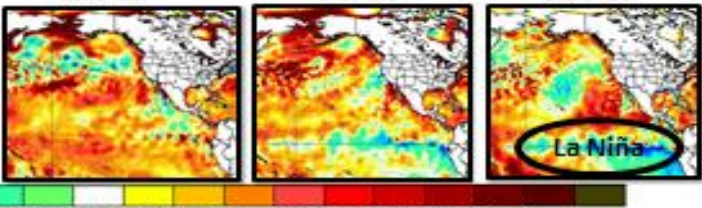

degrees $C$

Fig. 1. North Pacific sea surface temperature anomalies from July 2014 to December 2017, data from http://polar.ncep.noaa.gov/sst/ophi/ problem

$\underline{1-\text { Why understanding the mechanisms that regulate the abundance of Pacific salmon is an international }}$

There is a history of increasing and decreasing trends in the production of Pacific salmon. I will briefly describe a few of these trends as examples of the economic consequences of our inability to understand what is causing the trends. I am using these examples later in my presentation to hypothesize that there could be a common mechanism involved in all trends that is related to metabolic processes in the early marine period.

North Pacific commercial catches of chum salmon

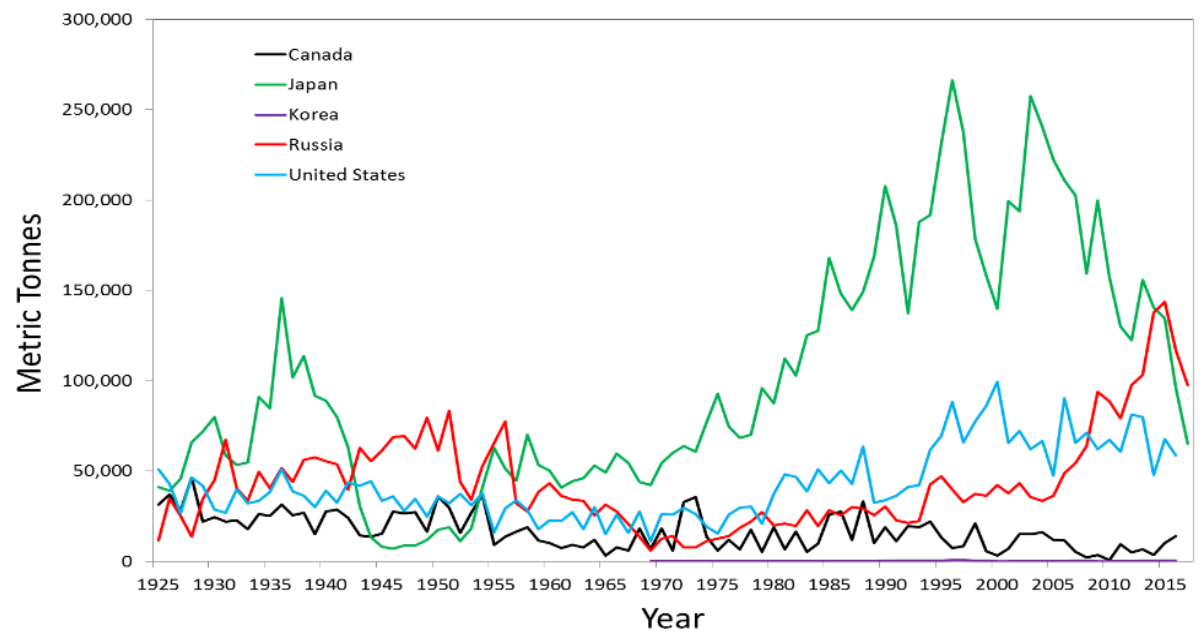

Fig. 2. North Pacific commercial catch of chum salmon by country. Data from North Pacific salmonid catch statistics (updated 31 July 2018). North Pacific Anadromous Fish Commission, Vancouver (Available: www.npafc.org).

There is a declining trend in the commercial catch of chum salmon by Japan that started about 2006 and continued through to 2017 (Fig. 2). The decline occurred despite an almost constant hatchery release of hatchery fish (from 1990 to 2016 the average hatchery release by Japan was about 2.0 billion fish and during the period of 
decline the average was 1.9 billion). Beginning at almost the same time of the declining trend, there has been an increasing trend in the catch of chum salmon from Russia (Fig. 2). Of relevance to an explanation for the declining trend of Japanese production is the knowledge that the juvenile chum salmon from Japan and Russia rear in the Sea of Okhotsk before migrating into the open North Pacific (Urawa et al. 2018). In a recent paper by Shuntov et al. (2018), the authors estimate that prey for juvenile Pacific salmon in the Sea of Okhotsk is not limiting the production of Pacific salmon, suggesting that the factors responsible for the declining trend of Japanese chum salmon are initiated before they enter the Sea of Okhotsk.

\section{Commercial catches of chum salmon in Alaska}

The commercial catch of chum salmon in Alaska increased in 1980 and again in the early 1990s with a record catch in 2017 (Fig. 3). Hatchery and wild catch estimates are available for Southeast Alaska showing that the major increase in catch is from hatchery fish (Fig. 4). However, as the increased catch occurred, there was an unexplained small decreasing trend in the wild chum catch. One possible explanation is that there is competition between the hatchery and wild fish with the more numerous hatchery juveniles reducing the availability of prey for the wild fish resulting in more energy used by wild fish to find food and less energy available for somatic growth or lipid storage for the winter. Another explanation could be that the releases of hatchery fish are better matched to periods of maximum prey production and benefit from being in the right place at the right time.

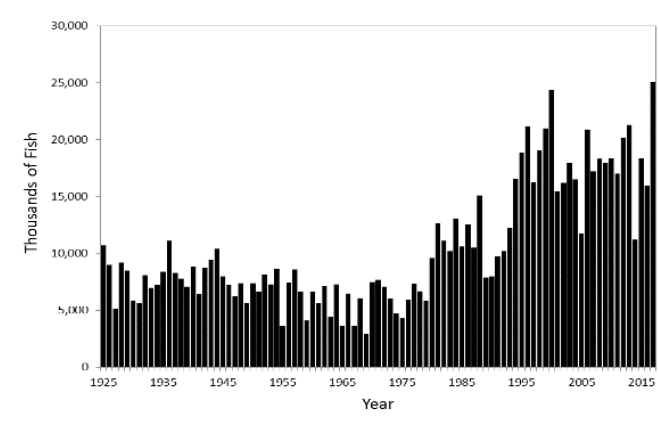

Fig. 3. Commercial chum salmon catch in Alaska. Data from North Pacific salmonid catch statistics (updated 31 July 2018). North Pacific Anadromous Fish Commission, Vancouver (Available: www.npafc.org).

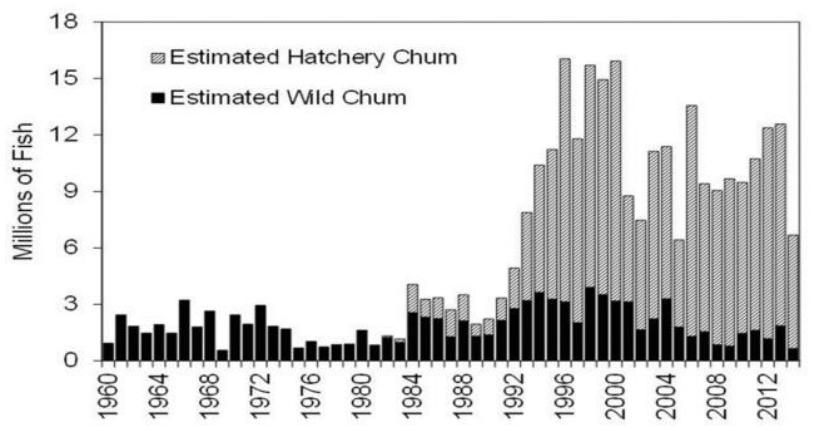

Fig. 4. Hatchery and wild composition of the commercial chum salmon catch in Alaska.

\section{Commercial catch of pink salmon in the North Pacific}

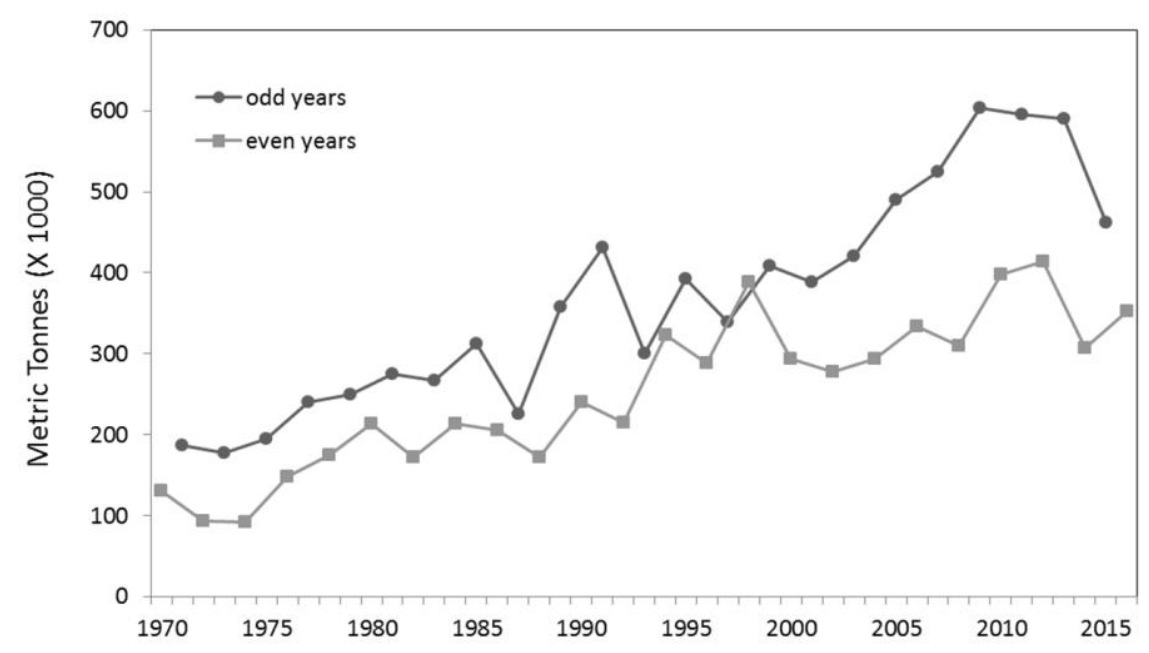

Fig. 5. North Pacific commercial catch of pink salmon by country. Data from North Pacific salmonid catch statistics (updated 31 July 2018). North Pacific Anadromous Fish Commission, Vancouver (Available: www.npafc.org). 
The commercial catch of pink salmon by all countries increased since 1970 and was 449,067 metric tons in 2017 (data from NPAFC Pacific salmonid catch statistics, updated 31 July 2018). From 1970 to 1999 , the catch trends of odd- and even-year pink salmon were similar, with the odd-year catches always exceeding the previous even-year catches (Fig. 5). Beginning in 2000, the catch trends of the two brood years changed, with the odd-year catches increasing at a much faster rate than the even-year catches. The increase was not a result of hatchery production as there was a $4 \%$ increase in the hatchery production in average even-year releases beginning in 2000. Accordingly, the odd-year fish must be experiencing improved production compared to the even-brood year. In a study by Wechter et al. (2017), the authors measured insulin-like growth factor, IGF-1 (Beckman et al. 2004) and energy densities of even- and odd-year juveniles in the northeastern Bering Sea. They observed differences in how the two brood years grew and stored energy in the first ocean year. They concluded that there was evidence that later in the first ocean year the even-year populations allocate more energy to lipid storage than to somatic growth than the odd-year populations. The even-year fish that stored more lipid for use in the winter, would be smaller and may have less appetite for growing in the winter as discussed for other species by (Biro et al. 2004). In contrast, the odd-year fish would be larger at the beginning of winter and would continue to feed and grow in the winter if prey were abundant. Importantly, this study produced one of the few publications that researched the mechanisms causing trends in production as the behaviour and response of the odd- and even-year pink salmon is a clue to the explaining the more general mechanisms that regulate growth and ocean survival of all Pacific salmon.

\section{Commercial catches of Chinook salmon}

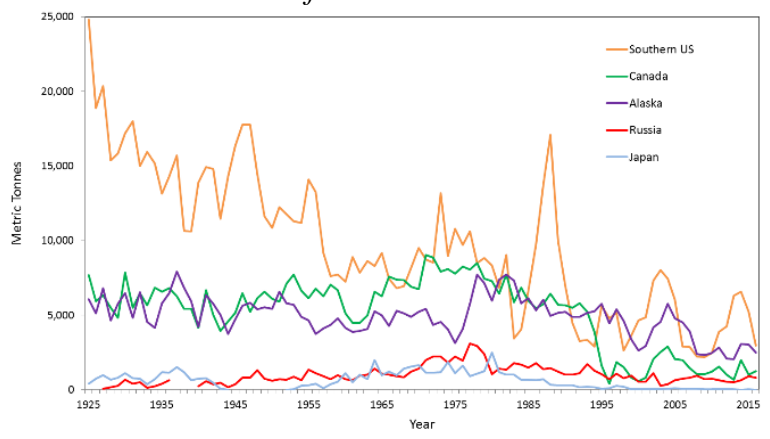

Fig. 6. North Pacific commercial catch of Chinook salmon by country. Data from North Pacific salmonid catch statistics (updated 31 July 2018). North Pacific Anadromous Fish Commission, Vancouver (Available: www.npafc.org).

Chinook salmon are mostly caught in North America. The total catches by all countries from 2000 to 2017 Averaged 9,969 metric tons with 93\% caught in North America (data from NPAFC Pacific salmonid catch statistics, updated 31 July 2018). Despite the very small catches, Chinook salmon are an iconic species in North America, because of their large size, value in the recreational fishery and cultural significance. The Commercial catches of Chinook salmon by all countries began to decline in the early 1980s (Fig. 6). Some of this decline related to regulation changes (Riddell et al. 2018), but the decline is mostly related to reduced productivity (Riddell et al. 2018). In recent years the declining trend in abundance off North America has become alarming as negotiators found out in the renegotiation of the Pacific salmon treaty between Canada and The United States. In British Columbia, the declining abundances are thought to be related to declining production of a group of iconic Killer Whales resulting in recent reductions in exploitation rates and area closures for the recreational fishery. An example of the declining trends in production is in the return of Chinook salmon to the Taku River that flows from British Columbia, Canada through Alaska and into the Gulf of Alaska at Juneau (Fig. 7). The data include estimates of harvest which are believed to have low exploitation rates of about 10 to $20 \%$. The point is that there is an unexplained declining trend and there are numerous trends like this from Alaska to California. Because the trends are basin scale, it is most likely that there is a common mechanism. A common mechanism such as reduced early marine growth could be exacerbated by other sources of mortality on larger individuals if these larger fish become less able to avoid predation. 


\section{Total returns of sockeye salmon to the Fraser River in British Columbia}

Sockeye salmon from the Fraser River in British Columbia produce what is probably the most important fishery on Canada's Pacific coast. The returning adult fish migrate into waters within the United States requiring the need for a management treaty between the two countries. The resulting Pacific Salmon Commission had its first meeting in 1937. The total returns are complicated by cycles that are almost consistently four years with one dominant run every fourth year (Fig. 8). There is a clear increasing trend in the total returns from about the early 1950s to 1993 and then a decreasing trend through to the present, with an historic high return in 2010 that produced a large return in 2014 (Fig. 8). In 2009, there was an unexpected very poor return after two previous poor returns. The poor returns and the inability to forecast the poor returns, so alarmed all involved that the Prime Minister of Canada commissioned a judicial enquiry to determine why the declines were occurring. The enquiry started its hearings in the summer of 2010, several months before the historic high return of 2010 (Fig. 8). The reasons for the historic high return were not considered. After two years and a cost that probably exceeded 40 million dollars, the judge considered that the reason for the poor return in 2009 was that ocean and climate conditions may have resulted in abnormally low phytoplankton and nitrate concentrations that could have led to poor zooplankton production (Cohen 2012). However, most people remember the judge's statement "some, I suspect, hoped that our work would find the "smoking gun"- a single cause that explained the two-decade decline in productivity". The judge could have equally included the previous three-decade increase in productivity. The message from this judicial exercise is that the judge did not identify the reason for the declining trend because he did not hear any scientific explanation of the mechanisms causing the declining trend. Thus, the importance of the inquiry may be not what was found but what was not found.

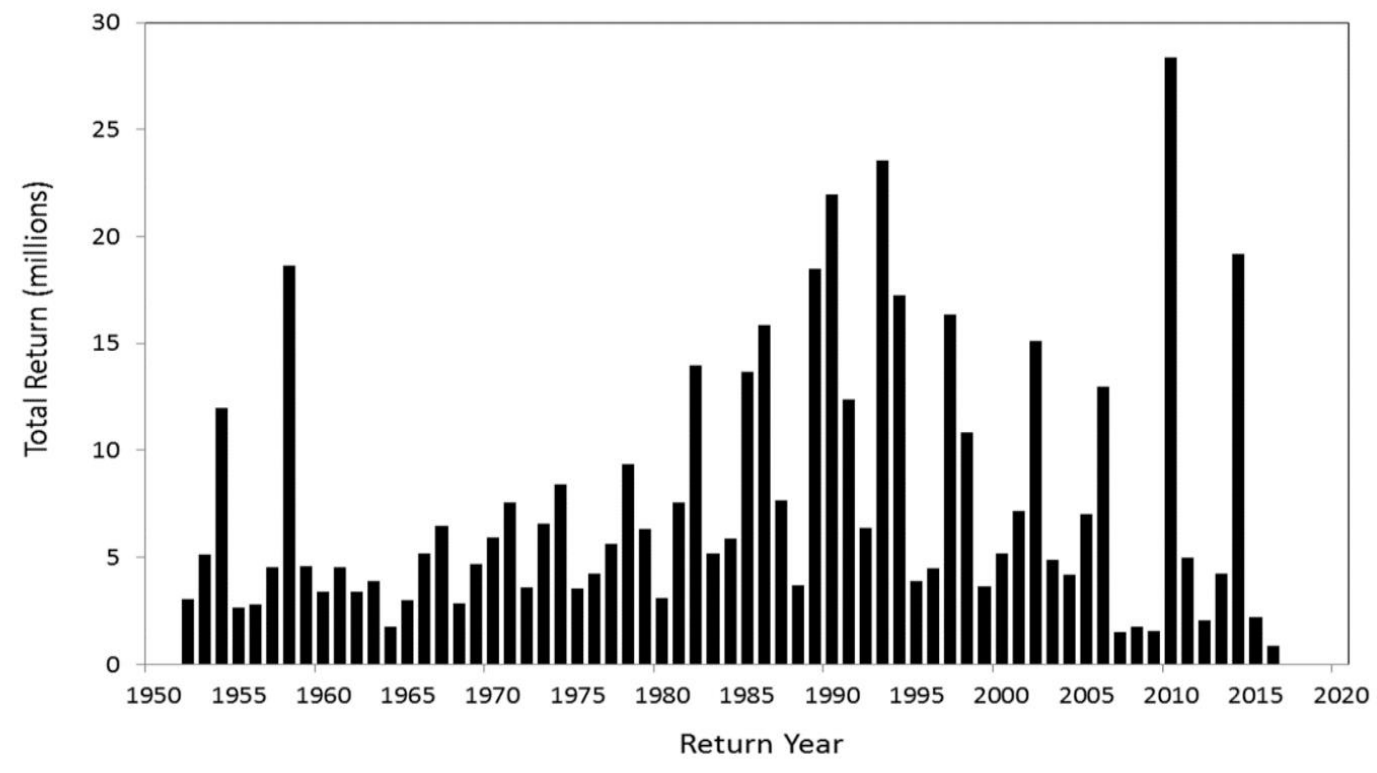

Fig. 8. Total return of sockeye salmon to the Fraser River, 1952-2016.

There is a recent unpublished study by Lyse Godbout at the Pacific Biological Station in Nanaimo that is a clue to what caused the very poor return in 2009 and the exceptionally large return in 2010. She found that the juveniles that produced the very poor return had very poor growth in the early marine period in the Strait of Georgia, while the juveniles that produced the very good return in 2010 had significantly greater growth in the early marine period. This is not an explanation of the trends, but it is evidence that individuals that have very good survival also have very good growth in the first four to six weeks in the ocean.

\section{Summary}

Production trends, as shown in the preceding examples, occur for different species of Pacific salmon in different oceans. Obviously the circumstances causing the trends may differ, but I propose that the underlying mechanisms that control the response of the individuals to the changes in their ecosystems may be similar. As mentioned previously, we cooperate internationally to solve important common problems such as complex medical issues. We could use the International Year of the Salmon to create teams that would use the same kind of 
international cooperation used for medical problems to identify the mechanisms that cause these trends and regulate Pacific salmon production. The message is that finding a cure for something is much easier when the cause is known.

\section{2-Hatcheries and salmon enhancement}

Hatchery reared Pacific salmon are now estimated to represent about $40 \%$ of the biomass of all Pacific salmon in the subarctic Pacific (Ruggerone and Irvine 2018). This clearly indicates that hatchery fish are a major contributor to the commercial and recreational economies of Pacific salmon producing countries. Hatchery production generally is considered to be a technology-based effort, inferring that the information needed to produce hatchery fish is mostly known. In contrast, wild salmon are recognized as being challenged by changing freshwater and ocean ecosystems with the understanding that there will be substantial changes to ocean ecosystems. For example, model predictions indicate that by 2050, most of the surface waters of the North Pacific will be 1.2 to 1.8 ${ }^{\circ} \mathrm{C}$ warmer (www.esrl.noaa.gov/psd/ipcc/). Thus, there are proposals to change management strategies for wild salmon to use a resilience-based approach and rely less on achieving target escapement numbers (Holling 1973, considered that resilience is the ability to absorb change; I am using the term resilience for hatchery production as the ability to respond to change). A resilience-based approach is intended to ensure more diversity for wild populations with the expectation that within this diversity, (and without understanding the mechanisms involved), there is an inherent ability to better adapt to whatever ecosystem changes occur. I proposed that a similar approach is needed for hatchery production - that is - hatchery production should rely on fish that are best adapted to the changing coastal ecosystems. Not having the natural resilience of wild populations, hatchery production will need to be adaptive and experimental. This may mean that producing hatchery fish is more difficult and expensive, but the production may be necessary to sustain economies if many wild fish populations are not able to adapt to the modern ocean ecosystems. Changing hatchery production from a technology-based approach to an adaptive-based approach is another example of the importance of working together internationally.

\section{Example of hatchery production in Japan}

The decline in production of chum salmon in Japan, discussed previously, (Fig. 2) could be explained as an inability of the chum fry to adapt to recent ecosystem changes in the coastal areas around Japan. There is a possibility that the decline in production is also related to their residency in the Sea of Okhotsk after they leave the coast of Japan. A paper by Shuntov et al. (2018) summarized the biological information collected from numerous scientific surveys starting in the 1980s by the Russian scientists from TINRO in Vladivostok. Using extensive nekton data and over 300,000 stomach analyses, they concluded that competition for food is not the most important factor limiting the abundance of juvenile Pacific salmon in the Sea of Okhotsk because there is no evidence of acute food shortages. For example, a possibility is that the Japanese fish are more susceptible to predation when they enter the Sea of Okhotsk, because they are less able to avoid predation. Identifying the reasons for the declining production of Japanese chum salmon is of international importance as the decline shows that large scale changes in hatchery production are possible throughout the North Pacific. A resilience-based approach would consider experimenting with stocks that are better adapted to growing faster and quicker when they enter the ocean. Understanding the mechanisms involved and using this understanding to release fish that are metabolically better adapted to survive in the changing coastal ecosystems may be the approach needed by all hatchery production in the future.

\section{Example of hatchery production in British Columbia}

A second example of the need to be more adaptive when producing hatchery fish is the history of producing hatchery Pacific salmon in British Columbia. In mid-1970s, the Canadian Government was advised that there was unused capacity in the ocean that could produce more Canadian Pacific salmon. The government was advised that the fastest way of producing more fish for the various fisheries was to produce hatchery fish. The Salmon Enhancement Program was officially started in 1977 and was expected to double the current commercial catch by 2005 with increases in abundance of all five species of Pacific salmon. By 2005, the commercial catch was less than $1 / 2$ of the catches in the 1970s (data from NPAFC Pacific salmonid catch statistics, updated 31 July 2018). There is no explanation of what went wrong. However, the current record high catches of Pacific salmon by all countries, which are about double the catches in the 1970s, are evidence that the carrying capacity of the North Pacific for Pacific salmon in the 1970s was capable of producing more salmon as originally thought. My interpretation of the failure to double production and the actual decline in production is that the capacity to support juveniles in the early marine period in the coastal areas of British Columbia declined in the 1980s resulting in higher marine mortality 
rates and reduced abundances. Similar to the situation in Japan, it may be possible for Canada to improve hatchery production on the Pacific coast if they become more adaptive by looking for ways to improve the growth of juveniles in the early marine period.

\section{Summary}

These two examples highlight the difficulties with the production of hatchery fish that have limited resilience to changing ocean ecosystems. With the almost certainty of major changes in ocean ecosystems, it is also almost certain that there will be more difficulties producing hatchery fish. I suggest that as part of an international effort to understand the mechanisms that regulate Pacific salmon production, there could be an increased focus on maintaining hatchery production in changing ocean environments. A new approach would be more adaptive. Key to this approach would be that hatchery production would be continuously experimental. Hatchery production would become a series of experiments making production more difficult, but eventually more predictable. Hatchery production could change from producing fish with homogeneous life histories to populations of fish with diverse life histories. The intent would be to improve the early marine survival. Importantly, adaptive hatchery production becomes more than releasing a suite of fish of populations at different times, as the approach is to ultimately understand the mechanisms that regulate the production and using the understanding identify populations that are best adapted to existing ecosystems. Importantly, there needs to be a greatly increased scientific interest in optimizing hatchery production in the changing ocean ecosystems. This could begin with an international symposium that is privately funded so that all experts can particirate.

3-An hypothesis of the mechanism regulating Pacific salmon production in the ocean

Richard Feynman was a Nobel Prize winning theoretical physicist. He responded to a question during one of his lectures by saying that, in general, he would look for a new law of physics by guessing the relationship and then computing the consequences. If the computations or experiments did not support the guess or hypothesis, then it was wrong. This is the approach we need to take as an international team of researchers to discover the mechanisms that regulate Pacific salmon abundance.

The critical size-critical period hypothesis originally proposed by Beamish and Mahnken (2001), was revised to emphasize the rate of growth up to a critical threshold which would be the critical period (Beamish and Neville 2016). The principle would be that rapid growth up to the critical period would ensure that the condition of the individual exceeded a metabolic threshold. Individuals with a condition exceeding the threshold would begin to store more lipids than individuals not exceeding the threshold. Fish that stored more lipids would have a better chance of surviving the first ocean winter. Fish not exceeding the condition the threshold would continue to use more lipids for somatic growth and consequently would have lower lipid levels in the winter and be more susceptible to mortality. I sometimes use the expression "dead fish swimming" to categorize the fish that were not programmed to store lipids for the winter. The intent of the revised hypothesis is the same as the original proposal, except that size relates to the amount of growth and condition that would allow an individual to exceed a critical threshold at a critical period. The critical period component of the hypothesis continues to be a genetically programmed threshold that is cued by an environmental stimulus such as day length at a genetically determined threshold in development. An individual that grows faster in the first weeks in the ocean, by maximizing energy used for growth, survives better because it can be larger and reduce predation threats and because metabolism is changed to begin to store more lipids. Critical sizes, metabolic thresholds, decision windows and similar concepts are commonly recognized mechanisms. It was relatively easy to find over 75 papers that addressed the topic of size thresholds and critical periods. For example, a well-known paper by Lorenz (1937), reported that "imprinting of an animal occurs only during a narrow defined period in the individual's life, the critical period, and the imprinted behaviour cannot be forgotten". His research showed that there are metabolic pathways that are programmed to be receptive for a very brief period. In another study, Shearer and Swanson (2000) hypothesized "that a metabolic hormone may be a critical signal to the reproductive system that there are sufficient energy reserves or that growth rate is sufficient to initiate maturation for the subsequent years". These authors and others have reported that decisions to mature can be many months before the fish begin to show signs of maturing. In the third example, Silverstein et al. (1998) hypothesized that sexual development of Chinook salmon occurs in two critical periods leading to gonadal development and sexual maturity. These critical periods would be set by environmental cues and at the critical period, individuals evaluate their development potential in terms of growth rate, size or stored energy or some combination of factors.

The critical size-critical period hypothesis could be a major mechanism regulating all salmon production. It would mean that fish that grow faster, quicker when they first enter the ocean, survive better. As Richard Feynman, 
advised, hypotheses need to be tested. According to the hypothesis, Japanese chum salmon production gradually declined because the growth rate of the fry when they entered the ocean gradually declined, probably because of reductions in preferred prey. Consequently, more energy was used in finding food and less energy was available for growth resulting in an increasing number of juvenile chum salmon not exceeding a condition threshold at a critical period. A test of the hypothesis would be to compare energy densities of Japanese and Russian chum salmon in the Sea of Okhotsk in the fall. The hypothesis could be supported if the energy densities of the Japanese chum salmon are lower and with a larger variance than the chum salmon from Russia.

\section{4-International cooperation and the International Year of the Salmon}

The International Year of the Salmon is intended to draw attention to the commercial and cultural importance of Pacific and Atlantic salmon. Part of this attention will identify the complexities of stewardship in a future of changing ocean and freshwater ecosystems. My original idea in suggesting that there be an International Year of the Salmon was to create opportunities for researchers to work together to understand the mechanisms that regulate the production of wild and hatchery Pacific salmon. Along with some colleagues, I am trying to organize a privately funded expedition to study the ecology of Pacific salmon in the Gulf of Alaska in the winter of 2019. Our main hypothesis is that brood year strength is mostly determined by the end of the first ocean winter. If I can obtain the funds, this will be the first comprehensive study of Pacific salmon in the Gulf of Alaska in the winter, a time when about 1/3 of all Pacific salmon are in the area. There needs to be more of these international expeditions as they will unite the scientific effort to discovering how best to manage wild and hatchery Pacific salmon production as ocean ecosystems change. We also need more international symposia that focus on major issues in the production of wild and hatchery salmon. The symposia need to be privately organized and funded so that all experts and young researchers, soon to be experts, can participate. My suggestion, especially to the younger researchers around the rim of the subarctic Pacific, is that you team up and work out the mechanisms that regulate the production of wild and hatchery Pacific salmon which I think will turn out to be quite simple. If individual researchers show that major advances can be made by teaming up internationally, it may provide the incentive for private funding and future government support.

Acknowledgements - Shigehiko Urawa is responsible for my participation in this conference. I am always encouraged by his quite determination to find ways to understand the mechanisms regulating Pacific salmon production. I most appreciated the opportunity to be back in Japan. Leon Shaul provided the figures for catches in Alaska and returns of Chinook salmon to the Taku River. Laurie Weitkamp produced Fig. 1. Lana Fitzpatrick helped with the preparation of the paper.

Note-The Japanese version of this article is published in Aquabiology 40(5).

\section{REFERENCES}

Beamish, R.J., and C. Mahnken. 2001. A critical size and period hypothesis to explain natural regulation of salmon abundance and the linkage to climate and climate change. Prog. Oceanogr. 49: 423-437.

Beamish, R., and C. Neville. 2016. Applying the Krogh Principle to find shortcuts to understanding Pacific salmon production. N. Pac. Anadr. Fish. Comm. Bull. 6: 455-468. (Available at http://www.npafc.org)

Beckman, B.R., M. Shimizu, B.A. Gadberry, and K.A. Cooper. 2004. Response of the somatotropic axis of juvenile coho salmon to alterations in plane of nutrition with an analysis of the relationships among growth rate and circulating IGF-I and 41kDa IGFBP. General and Comparative Endocrinology 135: 334-344.

Biro, P.A., M.V. Abrahams, J.P. Post, and E.A. Parkinson. 2004. Predators select against high growth rates and risk-taking behaviour in domestic trout populations. Proceedings of the Royal Society London B, 271: 22332237.

Cohen, B.I. 2012. The uncertain future of Fraser River Sockeye. Volume 3: Recommendations-summary-process (211 p). Ottawa ONL Minister of Public Works and Government Services Canada.

Holling, C.S. 1973. Resilience and stability of ecological systems. Annual Review of Ecology and Systematics 4: $1-23$.

Lorenz, K.Z. 1937. The companion in the bird's world. The Auk 54:245-273.

North Pacific Anadromous Fish Commission (NPAFC). 2018. NPAFC Pacific salmonid catch statistics (updated 31 July 2018). North Pacific Anadromous Fish Commission, Vancouver. (Available: www.npafc.org) 
North Pacific Anadromous Fish Commission (NPAFC). 2018. NPAFC Pacific salmonid hatchery release statistics (updated 31 July 2018). North Pacific Anadromous Fish Commission, Vancouver. (Available: www.npafc.org)

Riddell, B.R, R.D. Brodeur, A.V. Bugaev, P. Moran, J.M Murphy, J.A. Orsi, M. Trudel, L.A. Weitkamp, B.K. Wells, and A.C. Wertheimer. 2018. Ocean ecology of Chinook Salmon. Pages 555-696 in R.J. Beamish (Editor) The Ocean Ecology of Pacific Salmon and Trout. American Fisheries Society, Bethesda, Maryland.

Ruggerone, G.T., and J.R. Irvine. 2018. Numbers and biomass of natural- and hatchery-origin pink salmon, chum salmon, and sockeye salmon in the North Pacific Ocean, 1925-2015. Marine and Coastal Fisheries: Dynamics, Management, and Ecosystem Science 10:1-17.

Silverstein, J.T., K.D. Shearer, W.W. Dickhoff, and E.M. Plisetskaya. 1998. Effects of growth and fatness on sexual development of Chinook salmon (Oncorhynchus tshawytscha) parr. Can. J. Fish. Aquat. Sci. 55:23762382.

Shearer, K.D., and P. Swanson. 2000. The effect of whole body lipid on early sexual maturation of $1+$ age male Chinook salmon. Aquaculture 190: 343-367.

Shuntov, V.P., O.A. Ivanov, and E.P. Dulepova. 2018. Biocenoses and biological resources of subzones in the Sea of Okhotsk large marine ecosystem: their state and commercial use. Deep-Sea Research Part II, (in review).

Urawa, S., T.D. Beacham, M. Fukuwaka, and M. Kaeriyama. 2018. The ocean ecology of Chum Salmon. Pages 161-318 in R.J. Beamish (Editor) The Ocean Ecology of Pacific Salmon and Trout. American Fisheries Society, Bethesda, Maryland.

Wang, K., C. Deser, L. Sun, and R.A. Tomas. 2018. Fast response of the Tropics to an abrupt loss of Arctic Sea ice via ocean dynamics. Geophysical Research Letters 45: 4264-4272.

Wechter, M.E., B.R. Beckman, A.G. Andrews III. A.H. Beaudreau, and M.V. McPhee. 2017. Growth and condition of juvenile chum and pink salmon in the northeastern Bering Sea. Deep Sea Research Part II: Topical Studies in Oceanography 135: 145-155. 